\title{
Oropharyngeal Squamous Cell Carcinoma
}

National Cancer Institute

\section{Source}

National Cancer Institute. Oropharyngeal Squamous Cell Carcinoma. NCI Thesaurus. Code C8181.

A squamous cell carcinoma arising from the oropharynx. It predominantly affects adults in their fifth and sixth decades of life and is associated with alcohol and tobacco use. Human papillomavirus is present in approximately half of the cases. It is characterized by a tendency to metastasize early to the lymph nodes. When the tumor is small, patients are often asymptomatic. Physical examination may reveal erythematous or white lesions or plaques. The majority of patients present with locally advanced disease. Signs and symptoms include mucosal ulceration, pain, bleeding, weight loss, neck swelling, and difficulty speaking, chewing, and swallowing. Patients may also present with swollen neck lymph nodes without any symptoms from the oropharyngeal tumor. The most significant prognostic factors are the size of the tumor and the lymph nodes status. 